\title{
Hindlimb morphology of Palaeotis suggests palaeognathous affinities of the Geranoididae and other "crane-like" birds from the Eocene of the Northern Hemisphere
}

Gerald Mayr

Acta Palaeontologica Polonica 64 (4), 2019: 669-678 doi:https://doi.org/10.4202/app.00650.2019

The early/middle Eocene Palaeotis weigelti is a flightless bird, which occurs in the fossil localities Messel and Geiseltal (Germany). The species is assigned to the Palaeognathae and some authors considered it to be a stem group representative of the Struthionidae (ostriches). Even though several partial skeletons have been found, the osteology of $P$. weigelti is incompletely known. In the present study, new details of the hindlimb morphology of the species are reported based on unpublished and previously described fossils from the Geiseltal. These data show that the recently described Galligeranoides boriensis from the early Eocene of southern France is another representative of the Palaeotididae and the oldest record of the taxon. It is further noted that Palaeogrus princeps from the middle Eocene of Italy, which was previously assigned to the Gruidae (cranes), may be another representative of the Palaeotididae. Galligeranoides was before assigned to the North American Geranoididae, a taxon mainly known from hindlimb elements. The Geranoididae are usually considered to be closely related to the Asian Eogruidae and both taxa are currently classified in the Gruiformes (cranes and allies). However, as detailed in the present study, derived similarities suggest close affinities between the Palaeotididae and Geranoididae. Eogruids were identified as stem group representatives of the palaeognathous Struthionidae by some earlier authors, and if close affinities between Palaeotididae and Geranoididae are corroborated in future analyses, palaeognathous affinities of the Eogruidae need to be critically revisited.

Key words: Aves, Palaeotididae, Struthionidae, evolution, systematic, Paleogene, Germany.

Gerald Mayr [Gerald.Mayr@senckenberg.de], Senckenberg Research Institute and Natural History Museum Frankfurt, Ornithological Section, Senckenberganlage 25, D-60325 Frankfurt am Main, Germany. 
Attribution License (for details please see creativecommons.org), which permits unrestricted use, distribution, and reproduction in any medium, provided the original author and source are credited.

Fof Full text $(1,209.1 \mathrm{kB})$ 